\title{
Pilot Test of Water Reuse Technology on Pharmaceutical Wastewater
}

\author{
Liang Wenjuan \\ School of Municipal and Environmental Engineering \\ Shenyang Jianzhu University \\ Shenyang, China \\ liangwenjuan100@163.com
}

\author{
Yan Yong \\ School of Civil Engineering \\ Shenyang Jianzhu University \\ Shenyang, China \\ 120388619@qq.com
}

\begin{abstract}
Taking the effluent of secondary biological treatment in one pharmaceutical factory as the object of study, taking coagulation, ultrafiltration and reverse osmosis treatments as the core technologies of the water reuse pilot test, the application effects of treatment process were analyzed. The results showed that, the turbidity of the clarifier effluent was lower than $10 \mathrm{NTU}$, and the removal rate of COD was $15.7 \% \sim 48.8 \%$. Ultrafiltration system operated steadily, whose transmembrane pressure stabilized at $0.4 \sim 0.6 \mathrm{~kg} / \mathrm{cm} 2$. The turbidity of water produced is stable, which was controlled around $0.17 \sim 0.28$ NTU, and the removal rate was $85.79 \% \sim 97.45 \%$. The removal for COD was not very effective, and the overall removal rate was not higher than $60 \%$. The reverse osmosis operated steadily under high water flux, and the desalination effect was gradually optimized. The application of the coagulation, ultrafiltration and reverse osmosis on pharmaceutical wastewater reuse project was effective. The effluent of reverse osmosis could be used in most advanced processes of pharmaceutical process.
\end{abstract}

Keywords-pharmaceutical wastewater; coagulation; ultrafiltration; reverse osmosis; pilot test

\section{INTRODUCTION}

Compared with other industries, the pharmaceutical industry has the characteristics of complex raw materials, complicated production processes, varieties of products and so on ${ }^{[1]}$. The amount of wastewater produced in pharmaceutical production is large, also it has low biodegradability and poor water quality ${ }^{[2]}$. It is one kind of industrial wastewater which is the most difficult to be treated ${ }^{[3,4]}$. A large number of high concentration of organic polluted wastewater can be produced in the physical, chemical and biological treatment processes, such as fermentation, filtration, ion exchange, concentration, esterification and purification, etc ${ }^{[5]}$.There is a great deal of organic compounds which are difficult to be degraded in pharmaceutical wastewater, and most of them have strong toxicity and "three role" function ${ }^{[6]}$. Fenton advanced oxidation process, three-dimensional electrode method, micro electrolysis, aerobic process, and membrane technology all can be used in the treatment of high concentration pharmaceutical wastewater ${ }^{[7]}$. Among them, the application of membrane technology is becoming more and more extensive ${ }^{[8]}$. Especially, duel- membrane technology is one of the hot spots in the international development and engineering application ${ }^{[9]}$. Ultrafiltration can remove most turbidity and organic compounds in the wastewater, which can reduce the pollution of the reverse osmosis membrane, prolong the service life of membrane and reduce the operating cost of the membrane engineering ${ }^{[10]}$. Reverse osmosis membrane can not only effectively remove organic compounds, reduce COD, but also has good desalination effects ${ }^{[11]}$. The high-quality effluent can be directly reused in the pharmaceutical industry, meanwhile, the concentrated water backflow to the conventional process, achieving zero emissions of wastewater and cleaner production ${ }^{[12]}$.

In this study, taking the effluent of secondary biological treatment in one pharmaceutical factory as the object of study, taking coagulation, ultrafiltration and reverse osmosis treatments as the core technologies of the water reuse pilot test, the application effects of treatment process were analyzed.

\section{TECHNOLOGICAL PROCESS AND MATERIALS}

\section{A. Technological process}

Taking the effluent of secondary biological treatment in one pharmaceutical factory as the object of study, water reuse pilot engineering was studied. The technological process: raw water tank --- dosing --- mechanical stirring clarification pool --- buffering tank --- ultrafiltration --water storage tank --- reverse osmosis.

The process was a combination of coagulation, ultrafiltration and reverse osmosis. Considering raw water containing a high concentration of organic suspended solids, adding coagulant and coagulant aid into mechanical stirring clarification pool, the effluent flowed into ultrafiltration device through the booster pump. By crossflow, the quality of concentrated water discharged from ultrafiltration device was better than influent. Concentrated water from ultrafiltration could return to mechanical stirring clarification pool entrance for secondary treatment. The product water from ultrafiltration flowed into the reverse osmosis water storage tank, and then through highpressure pump into reverse osmosis membrane module for desalination.

The product water was collected regularly for monitoring. 


\section{B. Experiment materials}

Coagulation equipment is mechanical stirring clarification pool. Coagulant is polyaluminium chloride (PAC), and coagulant aid is polyacrylamide (PAM). The types and dosage of chemicals are critical to operation. The dosage should change with influent turbidity (TABLE I ).

TABLE I. DOSAGES OF COAGULANT AND COAGULANT AID

\begin{tabular}{|c|c|c|c|}
\hline Influent Turbidity (NTU) & $\mathbf{< 2 0}$ & $\mathbf{2 2 0}$ & $>\mathbf{5 0}$ \\
\hline Dosage of coagulant (ppm) & 10 & 15 & 20 \\
\hline Dosage of coagulant aid (ppm) & 0.5 & 0.5 & 1.0 \\
\hline
\end{tabular}

Choosing Canadian SV6010B type ultrafiltration membrane for ultrafiltration process, and the United States Hyde LFC3-LD type which has high antipollution ability for reverse osmosis process, and this membrane module has been widely used in landfill leachate treatment, which has excellent antipollution performance.

\section{RESULTS AND ANALYSIS}

A. Operation analysis of mechanical stirring clarification pool

1) Effluent turbidity

The effluent turbidity of mechanical stirring clarification pool is shown in Fig .1.

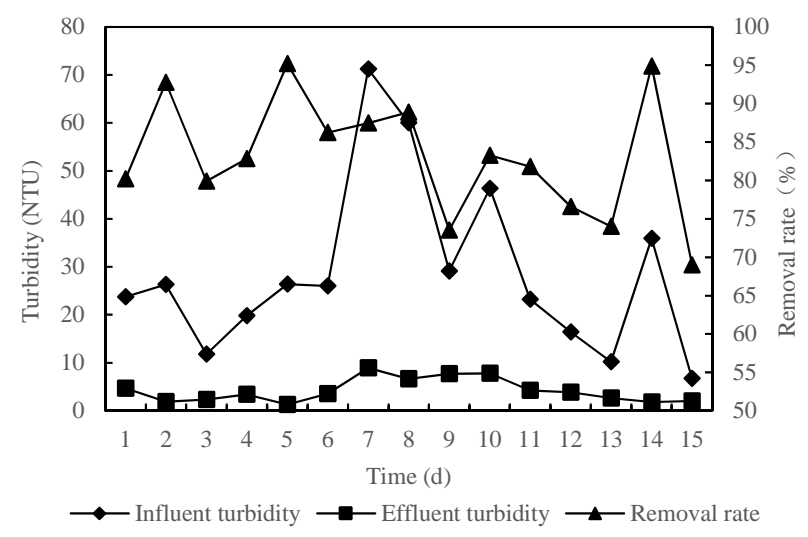

Figure 1. Influent and effluent turbidity and removal rate.

The turbidity removal efficiency of raw water in mechanical stirring clarification pool was excellent. Even if the turbidity of raw water was as high as $70 \mathrm{NTU}$, the effluent turbidity can also stabilize below 10 NTU. The average removal rate was $83.1 \%$ through coagulation. The peak values of removal rate had a good correlation with influent turbidity. Mechanical stirring accelerated clarifier was a buffering device for raw water fluctuation, through coagulation which could effectively remove the colloids that were critical threats to ultrafiltration and reverse osmosis membranes. Coagulation provided powerful guarantees for ultrafiltration and reverse osmosis's stable operation.

2) Removal efficiency of $C O D$

Flocculation not only ensured the removal efficiency of turbidity, but also had a high removal capacity for COD. the data is shown in Fig .2.

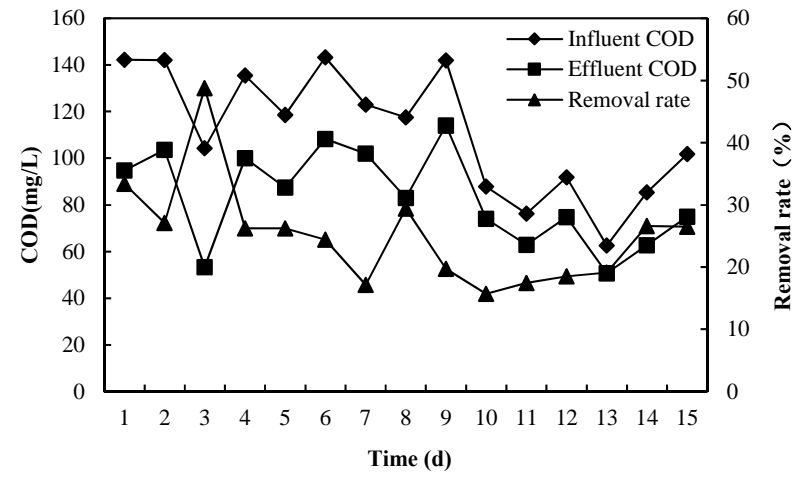

Figure 2. Removal rate of COD in coagulation treatment.

The removal rate of COD was between $15.7 \%$ 48.8\%, indicating that the content of insoluble organic matters in the raw water was large, and coagulation could effectively remove them. There was a good correlation between influent COD and effluent COD, and both peaks are almost synchronous.

\section{B. Ultrafiltration data analysis}

\section{1) Water yield}

The water yield of ultrafiltration membrane was stable at $2 \mathrm{~m}^{3} / \mathrm{h}$ (Fig .3), the concentrated water yield was 12 $\mathrm{L} / \mathrm{min}$.

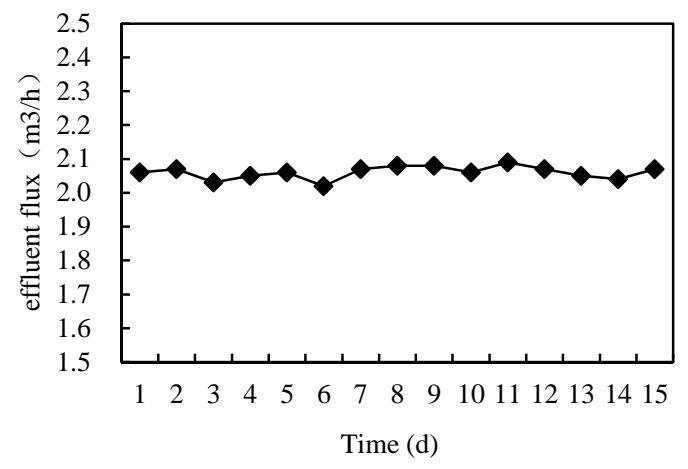

Figure 3. Water yield of ultrafiltration.

\section{2) Transmembrane pressure}

Transmembrane pressure fluctuated slightly with the running time, and was stable around $0.4 \sim 0.6 \mathrm{~kg} / \mathrm{cm}^{2}$ (Fig .4). The overall stability of the ultrafiltration system was good, and membrane fouling was not serious.

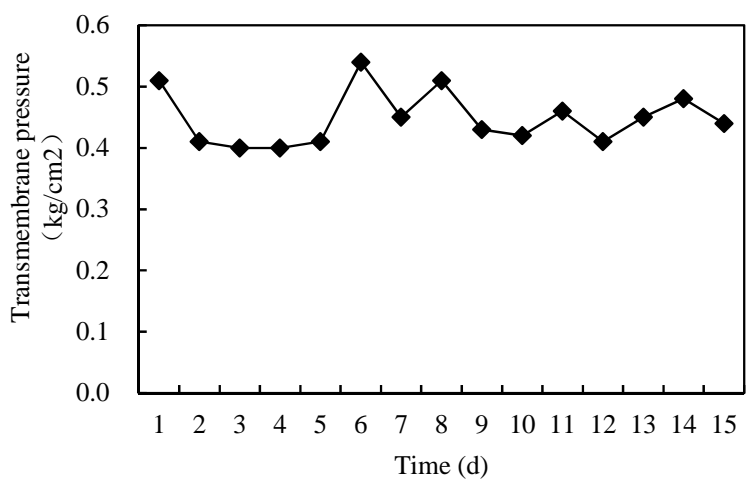

Figure 4. Change of transmembrane pressure of ultrafiltration. 


\section{3) Effluent turbidity}

Fig .5 describes the effluent turbidity and the removal rate in ultrafiltration treatment.

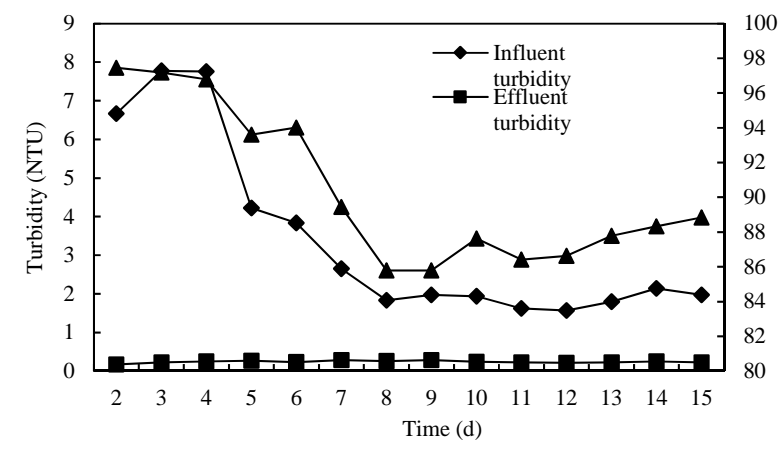

Figure 5. Influent and effluent turbidity and removal rate of ultrafiltration.

As shown in Fig .5, the water turbidity of the ultrafiltration system was stable around 0.17 0.28 NTU; the removal rate was $85.79 \% \sim 97.45 \%$, and the average was $90.85 \%$. The removal efficiency of turbidity was very good, and the removal rate was relatively stable, which could provide stable conditions for subsequent reverse osmosis system.

4) Effluent $C O D$

Effluent COD in ultrafiltration treatment is represented in Fig.6.

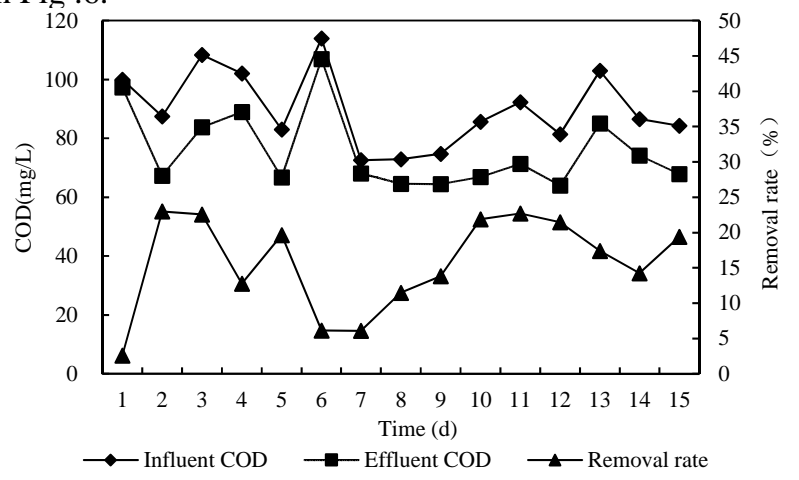

Figure 6. Influent and effluent COD change and removal rate of ultrafiltration.

Ultrafiltration system was not efficient for COD removal, and the overall removal rate was not higher than $60 \%$, which was mainly caused by a large number of small molecular soluble COD in the influent. It cannot be was removed by ultrafiltration membrane, which would bring certain pressure to subsequent reverse osmosis system.

\section{Reverse osmosis}

\section{1) Water yield and working pressure}

The water yield was $11 \mathrm{~L} / \mathrm{min}$; the concentrated water discharge was $6 \mathrm{~L} / \mathrm{min}$; the circulating water was $80 \mathrm{~L} / \mathrm{min}$; the recovery rate was $66 \%$; and the working pressure was $11.7 \mathrm{~kg} / \mathrm{cm}^{2}$. During the long term operation, the membrane pressure of reverse osmosis was very stable. There was no such phenomena as membrane fouling or concentration polarization. It indicated that the membrane module was suitable for the treatment of pharmaceutical wastewater. Controlling the washing time of reverse osmosis was the key to ensuring the overall stability and the cost of the system.

\section{2) Effluent conductivity}

Fig .7 is a continuous monitoring data of electrical conductivity of the reverse osmosis effluent.

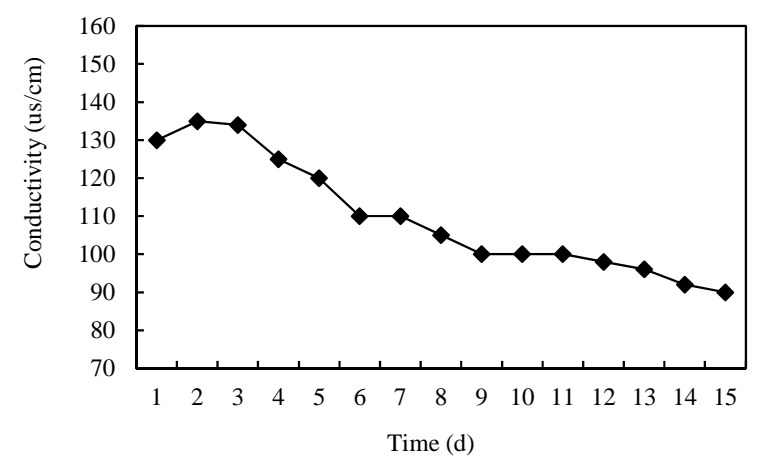

Figure 7. Effluent conductivity change of reverse osmosis.

The effluent conductivity of the reverse osmosis showed that, it slightly increased from $130 \mu \mathrm{s} / \mathrm{cm}$ in the first day to $135 \mu \mathrm{s} / \mathrm{cm}$ in the second day, then gradually decreased to $90 \mu \mathrm{s} / \mathrm{cm}$. Electrical conductivity decreased gradually, indicating that the desalination effect was gradually optimized. The amount of inorganic salt in the effluent would not influence the effluent reuse.

3) COD removal rate

Influent and effluent COD concentrations in reverse osmosis are shown in Fig .8.

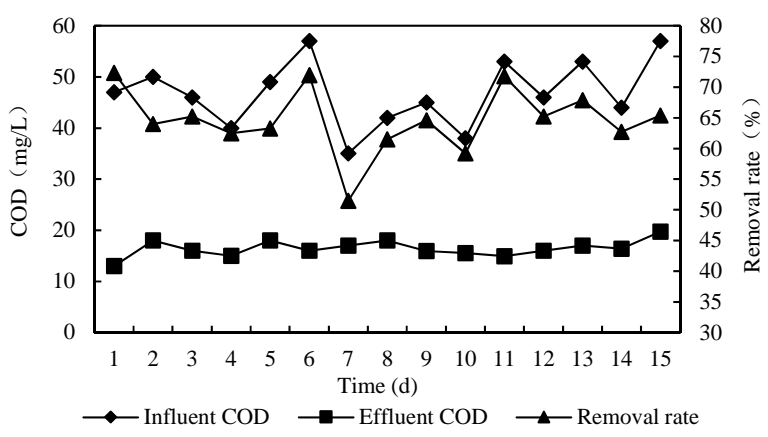

Figure 8. Influent and effluent COD concentrations and removal rate of reverse osmosis.

The COD average removal rate of reverse osmosis was $64.6 \%$, and the peak value was $72.34 \%$. The effluent COD was $13 \sim 20 \mathrm{mg} / \mathrm{L}$ with an average of $16.4 \mathrm{mg} / \mathrm{L}$. After reverse osmosis treatment, partial water could be used as the circulating cooling water.

The combination of ultrafiltration and reverse osmosis membrane lies in each membrane structure and pollution condition. The pore diameter of ultrafiltration membrane is relatively large, therefore, it is easy to form a gel layer in the membrane surface. This is due to the high turbidity being intercepted on the ultrafiltration membrane surface, and then forming serious concentration polarization; Even part of the solutes precipitate, form gel, and is adsorbed on the ultrafiltration membrane. The reverse osmosis membrane belongs to the dense membranes, and its superficial layer has permselectivity. On its surface there is also a thin pollution layer. This is mainly because the organic matters and minerals trapped will be adsorbed on the surface of the membrane. It is the ultrafiltration 
removing most of the turbidity that the pollution of reverse osmosis membrane can be greatly reduced.

\section{CONCLUSIONS}

In this study, taking effluent quality of secondary biological treatment in one pharmaceutical factory as research object, the application effects of reusing technology under pilot test were studied. The results showed that: (1) The raw water was added with coagulant and coagulant aid and flowed into the mechanical stirring clarification pool. The turbidity of the clarifier effluent was lower than $10 \mathrm{NTU}$, and the removal rate of COD was $15.7 \% \sim 48.8 \%$. (2) Ultrafiltration system operated steadily after dosing in coagulation treatment, and the transmembrane pressure stabilized at $0.4 \sim 0.6 \mathrm{~kg} / \mathrm{cm}^{2}$. The turbidity of water produced was stable, which was controlled around $0.17 \sim 0.28 \mathrm{NTU}$, and the removal rate was $85.79 \% \sim 97.45 \%$. The removal for COD was not very effective, and the overall removal rate was not higher than $60 \%$. (3) The reverse osmosis operated steadily under high water flux, and the desalination effect was gradually optimized. The application of the coagulation, ultrafiltration and reverse osmosis which is the core technology in pharmaceutical wastewater reuse project were effective. The effluent of reverse osmosis can be used in most advanced processes of pharmaceutical process.

\section{ACKNOWLEDGMENT}

This research was financially supported by the Shenyang Science and Technology Plan Project (F13-1443-00) and Special Major Science and Technology of Water Pollution Control and Management (2012ZX07202008002).

\section{REFERENCES}

[1] YANG Qi, SHANG Hai-tao, XI Hong-bo, et al. Pilot studies of UF-RO for municipal wastewater treatment [J]. Membrane Science and Technology, 2007, 27(3): 71-74.

[2] YOU Wei-jing, DENG Xian-tao, YANG Liang. Recycled water technological design of a cement plant in Shanxi Province [J]. Industrial Water Treatment, 2014, 34(12): 87-90.

[3] FAN Ju-hong, LIU Rui, YU Su-lin, et al. Effect of quality-based pretreatment on enhanced treatment of pharmaceutical wastewater [J]. China Water \& Wastewater, 2012, 28(23): 34-37.

[4] SONG Xin, REN Li-ren, WU Dan, et al. The present situation and research progress in the advanced treatment of pharmaceutical wastewater [J]. Guangzhou Chemical Industry, 2012, 40(12): 2931.

[5] LI Ya-feng, GAO Ying. Review on advanced oxidation processes for the degradation of disinfection by-product formation potential [J]. Technology of Water Treatment, 2014, 40(5): 1-4+9.

[6] DONG Kuo. Design of slaughterhouse wastewater treatment and water reuse [D]. Changchun: Changchun University, 2013, 24-69.

[7] YAN Jin-li. Application study on advanced treatment of textile wastewater by integrated ozonation-biological aerated filter process [D]. Chengdu: South China University of Technology, 2012, 21-39

[8] CHEN Hong-bin, LI Chen, LIU Fu-qiang, DAI Xiao-hu. Membrane bioreactor technology for treatment and reuse of mixed domestic wastewater from residential areas [J]. Journal of Tongji University ( Natural Science), 2013, 41(2): 247-252+288.

[9] ZENG Hang-cheng, ZHANG Guo-liang, MENG Qin. Treatment of textile wastewater using ultratfiltration and reverse osmosis dualmembrane system [J]. Chinese Journal of Environmental Engineering, 2008, 2(8): 1021-1025.

[10] LIU Shi-nian, HU Yong-you, YAN Jia, et al. Treatment of electroplating wastewater by coupling vacuum membrane distillation and membrane gas absorption [J]. Technology of Water Treatment, 2015, 41(3): 68-70+75.

[11] Fersi C, Gzara L, Dhahbi M. Treatment of textile effluents by membrane technologies [J]. Desalination, 2005, 185: 399-409.

[12] JIN Ke-yong, HU Jian-geng, JIN Shui-yu, et al. Comparison and optimization of zero discharge processes for treating reclaimed ro salinity wastewater [J]. Technology of Water Treatment, 2015, 41(1): 103-106. 